\title{
IMBRICAÇÕES ENTRE CULTURA POLÍTICA E RELIGIÃO: UM COMPARATIVO ENTRE A ÁREA ANDINA E O BRASIL
}

\author{
Diego Airoso da Motta
}

Resumo: O presente artigo trata da relação entre cultura política e religião, com ênfase na América Latina, especialmente na área andina e no Brasil. De forma incidental, é realizado também um superficial cotejamento entre o panorama latinoamericano e o mundo desenvolvido, o ocidente representado por Europa e Estados Unidos, em relação ao peso da religiosidade na formação da cultura política desses locais. O papel da religião na América Latina, outrora substancialmente católica, hoje presenciando o crescimento do movimento neopentecostal, é avaliada tanto no cenário dos populismos andinos, quanto no jogo político brasileiro. Ainda em termos de Brasil, é feita uma referência especial ao papel da Igreja Católica na formação de uma sociedade civil engajada e atuante, principalmente durante o regime ditatorial pós1964 .

Palavras-chave: Cultura política, Religião, América Latina.

Resumen: Este artículo aborda la relación entre cultura política y la religión, con énfasis en América Latina, especialmente en la región andina y Brasil. Por cierto, también se lleva a cabo un examen superficial entre el panorama de América Latina y el mundo desarrollado, representado por Europa occidental y los Estados Unidos, el peso de la religión en la formación de la cultura política de estos lugares. El papel de la religión en América Latina, antes sustancialmente católica, ahora viendo el crecimiento del movimiento pentecostal, se evalúa tanto en el escenario de los movimientos populistas de los Andes, como en el juego político en Brasil. Incluso en términos de Brasil, se hace una referencia especial al papel de la Iglesia Católica en la formación de una sociedad civil activa y comprometida, especialmente durante la etapa post-1964 la dictadura.

Palabras-clave: Cultura política, Religión, América Latina.

Abstract: This article deals with the relationship between political culture and religion, with emphasis on Latin America, especially in the Andean region and Brazil. Incidentally, is also carried out a superficial examination between the panorama of Latin America and the developed world, represented by Western Europe and the United States, the weight of religion in shaping the political culture of these places. The role of religion in Latin America, substantially Catholic before, now seeing the growth of the Pentecostal movement, is evaluated both in the scenario of Andean populist movements and the political brazilian game. Even in terms of Brazil, is made a special reference to the Catholic Church's role in the formation of an active and engaged civil society, especially during the post-1964 dictatorship.

Key-words: Political culture, Religion, Latin America. ${ }^{1}$ Graduado em Ciências Sociais e mestrando do Programa de Pós-Graduação em Ciências Sociais na
Universidade do Vale dos Rios dos Sinos - UNISINOS. Bolsista CAPES-PROSUP. 


\section{TÓPICOS INTRODUTÓRIOS}

A complexidade do sistema político nunca foi negligenciada pelas ciências sociais, que a reconhece através de uma profusão de estudos dedicados a analisar as implicações do mais diversos fenômenos que envolvam as disputas pelo poder: os diversos fatores que atuam sobre, influenciando e, no limite, condicionando a tomada de decisões; a forma como a política exerce efeitos na vida cotidiana da população; os processos eleitorais; o jogo de forças dentro dos parlamentos e entre os diferentes poderes do Estado; as dinâmicas internas- políticas e administrativas- deste Estado e sua relação com a sociedade, entre outros temas.

Dentre os elementos que colaboram para ampliar essa complexidade está, paradoxalmente, o crescente papel da religião na política. Paradoxal porque, desde o Renascimento, momento que inaugurou a modernidade há mais de cinco séculos, passando pelas revoluções liberais dos séculos XVII e XVIII, o mundo tem vivido um processo de secularização que abrange as mais diversas instâncias sociais, inclusive a política. Ainda assim, a religião nunca deixou de ocupar um papel de alta relevância nesse contexto. Embora de fato tenha deixado de ser o mais importante deles, ao menos no ocidente, dividindo espaço com toda a ordem de fatores. E, mais do que isso, não só continua a influenciar na compreensão de mundo das pessoas ${ }^{2}$ como, de um passado recente para cá, tem tendido a ampliar essa influência.

Hoy en día, como afirmó Erich Fromm, las grandes instituciones que administran los credos religiosos han llegado a un acuerdo tácito de convivencia con las sociedades irreligiosas del presente: a las iglesias les queda la labor marginal de brindar de modo ocasional "consuelo, aliento y esperanza". [...] En innumerables ocasiones la fe religiosa se ha convertido en un instrumento relativamente eficaz para mantener incólume el edificio axiológico que subyace a cualquier ordenamiento sociopolitico (MANSILLA, 2007, p. 38).

O drama maior desse diagnóstico é que ele se dá inclusive no núcleo do ethos moderno racional ocidental: os Estados Unidos. Habermas (2007, p. 131) bem aponta esse quadro3:

\footnotetext{
2 Para Habermas (2007, p. 144), a religião ocupa uma "posição" privilegiada "na vida das pessoas crentes. Porquanto a pessoa piedosa encara sua existência 'a partir' da fé. E a fé verdadeira não é apenas doutrina, conteúdo no qual se crê, mas também fonte de energia da qual se alimenta a vida inteira do crente”.

3 Habermas (2007, p. 133) revela a força da religião na cultura política americana, exemplificada na reeleição de George W. Bush em 2004: "De qualquer modo, o presidente Bush deve a sua vitória a uma coalizão de eleitores cujos motivos predominantes eram religiosos. Ora, tal deslocamento dos pesos políticos revela uma modificação mental correspondente que ocorre na sociedade civil. E esta também forma o pano de fundo para as controvérsias acadêmicas sobre o papel da religião no Estado e na esfera pública”.
} 
No período após o final da Segunda Guerra mundial, todos os países da Europa, com exceção da Irlanda e da Polônia, foram atingidos por uma onda de secularização, que acompanha os passos da modernização social. Nos Estados Unidos, porém, todas as pesquisas de opinião confirmam que a elevada porcentagem dos cidadãos religiosamente ativos permaneceu relativamente constante durante os últimos sessenta anos (grifos meus).

A consequência desse fenômeno nos processos políticos não é difícil de ser estimada, uma vez que tal panorama se forma precisamente no cisma do ocidente em relação à segunda guerra do Iraque (a dos anos 2000), em que a Europa não "abraçou a causa" dos EUA, no que Habermas (2007) chama de um reforço em termos culturais a uma divisão gestada no âmbito político.

[...] parece que, após a eliminação da pena de morte, com as regulamentações liberais do aborto, com a recusa incondicional da tortura, com a equiparação das orientações sexuais e com a paridade de conúbios homossexuais e, em geral, com o acento nos direitos e não nos bens coletivos tal como, por exemplo, a segurança nacional, os países da Europa continuam a trilhar, sozinhos, o caminho que tinham encetado, desde a época das duas revoluções constitucionais do final do século XVIII, junto com os Estados Unidos. Nesse ínterim, cresceu no mundo em geral a importância das religiões no contexto político. E nesse horizonte, a divisão do Ocidente é interpretada como se a Europa se isolasse do resto do mundo (HABERMAS, 2007, p. 131).

A Europa e sua "insistência" na racionalização secular passa a ser vista como uma exceção à regra mundial de não separar crenças e convicções religiosas do sistema político, já que "pelo ângulo de uma história mundial, o 'racionalismo ocidental', de Max Weber, passa a ser encarado, agora, com um caminho que foge à normalidade" (HABERMAS, 2007, p. 131).

Por tudo isso, o peso da religião não só na política em si, mas também na constituição de uma cultura política, isto é, no conjunto de atos e representações que dão sentido à política sob o ponto de vista de seus atores, é algo que engloba o mundo inteiro e desde um passado distante, o que não deixa de ser observado pelos agentes e grupos políticos de nosso tempo.

Puesto que las estructuras humanas, y más aun aquéllas del campo sociopolítico, precisan de un fuerte mecanismo consolidatorio, la religión ha jugado evidentemente el rol de factor legitimador de los regímenes más diversos a lo largo del desenvolvimiento histórico. Esto es válido sobre todo en lo que se refiere a la religión como institución y menos en cuanto creencia (MANSILLA, 2007, p. 37).

Nesse sentido, a análise desse tema se faz necessária também sobre a realidade latino-americana, que historicamente sempre esteve exposta às influências modernizantes ocidentais, em termos econômicos, políticos e culturais. 
Metodologicamente baseada em um enfoque teórico, concebido por meio de revisão bibliográfica fundamentada em autores europeus, latino e norte-americanos, é essa análise que o presente artigo se propõe a fazer, com especial ênfase no recorte sociogeográfico da área andina (sobretudo Equador, Bolívia e ainda Venezuela) e do Brasil, cada um com um desenvolvimento histórico muito peculiar no contexto da América Latina, mas cuja processualidade se inicia ainda durante as colonizações espanhola e portuguesa (ambas caracterizadas por fortes relações entre Estado e Igreja), se intensifica no séc. XX e se manifesta em nossos dias. A questão que norteia esta pesquisa é: qual é a relação entre cultura política e religião na América Latina, especialmente na área andina e no Brasil e como isso se manifesta na atual dinâmica política da região?

Composto efetivamente por apontamentos, ou seja, registros escritos sobre o tema proposto que, longe da pretensão de esgotá-lo, têm o intuito de indicar alguns de seus aspectos relevantes - o estudo se divide em quatro seções, linearmente organizadas num gradual que tenta ir do geral ao específico, nos limites da temática proposta e da metodologia empregada. Na primeira, mais conceitual, serão trabalhadas algumas noções preliminares sobre cultura política. Na segunda seção, mais analítica, serão tratadas algumas características da cultura política na América Latina, sobretudo o papel da religião em sua elaboração e mais especificamente a função da religiosidade popular no sucesso do populismo na região. No terceiro ponto, também de cunho mais analítico, será vista a relação entre religião e cultura política no passado recente do Brasil, com destaque para a luta contra a ditadura militar que comandou o país entre 1964 e 1985 e o avanço do neopentecostalismo sobre a política institucional brasileira, principalmente na última década. Por fim, serão traçadas algumas considerações sobre o tema abordado, a título de fechamento dos escritos ora apresentados.

\section{NOÇÕES CONCEITUAIS SOBRE CULTURA POLÍTICA}

Trata-se a cultura política de um ramo da ciência política e da sociologia que se dedica a estudar a subjetividade política que se objetiva quando perdura no tempo, isto é, o comportamento coletivo e o conjunto de características politicamente relevantes de uma sociedade, especialmente os valores que o orientam, os pontos de vista e as atitudes dos eleitores, dos militantes partidários e da elite política (MANSILLA, 2010).

Conforme Castro (1998), foram Gabriel Almond e Sidney Verba que introduziram o conceito de cultura política, a partir da obra The civic culture: political attitudes and democracy in five countries, de 1963. 
A tese que embasa todo aquele trabalho é a de que existe uma relação causal entre a opinião da população e a possibilidade de surgimento do sistema democrático e sua estabilidade. É importante considerar que essa hipótese subverte o caminho usual da análise política de até então: segundo ela, o centro explicativo da política deixa de ser as instituições políticas e passa a ser o eleitorado, com suas atitudes e ações (CASTRO, 1998, p. 31).

Haveria, portanto, uma relação direta entre a estabilidade democrática e o comportamento do eleitorado, expresso em suas opiniões e atitudes apuráveis em pesquisas e outras técnicas. Em outras palavras, as manifestações dos cidadãos, através de suas opiniões e atitudes, se estruturam em relação ao sistema político e o refletem e permitem sua compreensão.

Rokeach (1981), ao estudar a cultura política na América Latina, verificou que ela se forma por uma cadeia constituída por três instâncias: as opiniões (ou crenças), superficiais, em número elevado e mais voláteis; as atitudes; os valores (profundos, menos numerosos e mais estáticos). Essa diferenciação, apesar de ser importante em termos de entendimento da composição da cultura política, tem tendido a não ser utilizada nos estudos atuais, uma vez que seus limites se mostram pouco definidos e altamente flexíveis (MANSILLA, 2010).

As opiniões, precárias e cambiantes, são mais fáceis de serem apreendidas de forma direta e documentadas empiricamente em pesquisas. Os valores só podem, via de regra, ser interpretados a partir da análise dos outros dois elementos, já que estes os determinam.

O vetor de estudo, normalmente, se dá das opiniões para os valores, enquanto a linha de determinação destes fatores se movimenta no sentido contrário. Isto é, a partir dos valores se estabelecem as atitudes, que por sua vez dão causa às opiniões. Essa ordem, entretanto, pode se apresentar de outras formas, já que, embora mais raramente, as opiniões podem se sedimentar através da dinâmica das instituições sociais (como a família, a escola, os meios de comunicação...), se transformando em valores, e estes, por sua vez, podem se volatilizar em opiniões e crenças pouco duráveis (MANSILLA, 2010).

Almond (1972) faz importantes estudos comparativos sobre cultura política. Analisando diferentes orientações civilizatórias, classificou-as em função da abertura à democracia que apresentam. Assim, estabeleceu uma escala decrescente que se inicia com a cultura política ocidental, passa pela latino-americana, a islâmica e chega à cultura política africana sub-saariana. Sendo que a primeira se caracteriza como a mais democrática, por ser mais individualista e plural, e a última mais autoritária e 
coletivista. Essa orientação se baseia nos estudos comparativos de Max Weber sobre a influência de fatores culturais, como a religião, no campo político e econômico.

Almond trabalha a ideia de cultura cívica, caracterizada pela "constituição de cidadãos politicamente participativa" e necessária "para manter um sistema democrático estável” (BAQUERO, 1998, p. 14), na qual as culturas políticas norteamericana e europeia, mais precisamente a britânica, servem de referência positiva às demais, proposição que não deixa de ser amplamente criticada, uma vez que desconsidera as peculiaridades históricas de cada contexto em que se formam (CASTRO, 1998). Segundo esta concepção, a separação entre religião e política afastou esta de elementos coletivistas, em um horizonte em que o individualismo é a visão de mundo a orientar as escolhas políticas. Essa separação se dá principalmente no cristianismo. O islamismo, por sua vez, tem uma cultura que não separa religião e política. O Alcorão, diferentemente dos evangelhos, é a própria palavra de Deus, não dando margem à interpretação humana. Logo, o poder e a religião não podem ser interpretados e separados pelo homem. Os evangelhos são a palavra de Deus interpretada pelos homens que o escreveram, já havendo aí uma ruptura original entre um elemento e outro.

\section{A CULTURA POLÍTICA NA AMÉRICA LATINA: O PAPEL DA RELIGIÃo}

Véliz (1984) atribui à religião um papel fundamental na formação da cultura política latino-americana, especificamente no que se refere à Igreja Católica, cuja influência, para este autor, foi negativa. Na América Latina, a Igreja era totalmente comandada pelas coroas espanhola e portuguesa, sendo assim um apêndice do Estado, tipicamente centralista e, no caso da Espanha, extremamente rígido.

Segundo Véliz (1984), os espanhóis que vieram para a América Latina, originários especialmente da Andaluzia e da Extremadura, mantinham fortes traços culturais muçulmanos e eram relativamente pobres, diferente do habitantes do norte da Espanha e da região da Catalunha. Por isso, na América hispânica se formou uma cultura política caracteristicamente centralista e autoritária, própria da herança islâmica. O islã tem uma forte coesão social baseada no princípio de que o pluralismo pode facilmente se transformar em "politeísmo", algo veemente refutado pela cultura muçulmana, para a qual só existe um Deus e nenhum intermediário. Esse monismo se reflete na cultura política trazida pelos espanhóis do sul à América Latina e que fundamentaria o apreço pelos caudilhos proponentes de uma verdade pública única.

Entretanto, esse determinismo cultural presente na visão de Véliz (1984) se mostra débil perante os críticos, pois preconiza que esta dimensão simplificadora teria, 
ainda em nossos dias, uma preponderante influência sobre a cultura política na América Latina que, em verdade, é altamente complexa, tendo como uma das principais características de seus fenômenos políticos sua multicausalidade. Em outras palavras, a herança religiosa muçulmana pertence ao universo causal da cultura política latino-americana em seus traços centralistas e autoritários, mas não é o único elemento que lhe explica e quiçá não seja o mais importante.

Segundo Morandé (1984), a religiosidade na América Latina apresenta poucos elementos intelectuais. Mesmo no momento em que foram implantadas as primeiras universidades na região, não se produziam estudos teológicos sobre a religiosidade na época colonial. O trabalho intelectual era apenas de divulgação, não de criação.

Prevalece, desde então, uma religiosidade não-intelectual de caráter prático, ritualístico, que promove a solidariedade social, a filantropia, é propensa ao culto de imagens e à valorização das cerimônias, das procissões e da arquitetura dos templos.

É bem presente na religiosidade popular latino-americana, especialmente na área andina, a cultura barroca, com fortes elementos sincretistas, misturando práticas animistas pré-colombianas com um catolicismo não ortodoxo. Os colonizadores partiam da ideia de que os indígenas não tinham capacidade de assimilar a religião católica. Logo, os colonizadores e a Igreja eram permissivos nesse sentido; não impunham autoritariamente uma sistemática cultual rígida.

A base dessa religiosidade era uma solidariedade fraternal que se reflete no sincretismo. Sua expressão marcante é a tendência à festividade como momento integrador - como o Carnaval, de larga relevância no Brasil - de origem não burocrática, sem mediações racionais.

A religiosidade popular não é escrita, é prática. Não sendo, dogmática, não há como compor um corpo "burocrático" que doutrinariamente zele pelos cultos e pela fé “corretos”. Não há a defesa de uma tradição, um "tradicionalismo". É possível, por exemplo, substituir elementos usados nos rituais por outros menos onerosos, como animais de grande porte por menores ou mesmo objetos de pequeno valor.

\section{Ligações entre religiosidade popular e populismo na área andina}

Em seus estudos, Oakeshott (1998) fala que as classes médias e altas tendem a instrumentalizar as religiões. Não são efetivamente "religiosas", mas utilizam de algumas práticas - como o batismo, o casamento no âmbito religioso... - visando conquistar colocação social. Via de regra, têm uma posição agnosticista, quase indiferente à religião. Não são necessariamente ateístas, mas fogem à discussão. São um tanto céticas sobre a ética religiosa. Esta atitude - sobretudo na área andina, muito 
pobre - é vista pelas classes populares como cinismo, desconfiando de toda intervenção religiosa das outras classes. O fervor religioso, então, está de fato ligado às classes populares.

Por conta disso, estas classes - na área andina, principalmente - têm uma tendência a seguir propostas políticas que unam fé, moral e política, que pareçam encarnar uma moralidade que negue o ceticismo e o pragmatismo.

Nessa região, verifica-se um aumento significativo das religiões protestantes neopentecostais e religiões animistas, com uma relevante tendência a apoiar as orientações neopopulistas ${ }^{4}$. Essas religiões não valorizam a dimensão intelectualteológica, mas sim a dimensão ritualística, de efeito mais psicológico, o que traz a seus seguidores, de forma até imediata, bem-estar, sensação de solidariedade e irmandade com os demais fiéis. Destaca-se a característica do assembleísmo, em que os seguidores se sentem membros de um organismo vivo, onde são ouvidos. Há a valorização da atenção às necessidades psíquicas, o que os partidos neoliberais - contraponto político das agremiações populistas - normalmente não percebem, da mesma forma que os partidos tradicionais de esquerda, mas que, por outro lado, os partidos populistas apreendem e utilizam em seu proveito.

De fato, os atuais governos populistas da América Latina, sobretudo na região dos Andes, não favorecem nenhuma religião, nem mesmo as neopentecostais. Contudo, é interessante formular a pergunta no sentido contrário: por que estes movimentos religiosos apoiam o populismo?

$\mathrm{Na}$ área andina, especialmente na Bolívia, a Igreja Católica ao longo do tempo tem tido boa parte de suas propriedades (as que não tinham uso específico para cultos) estatizadas, o que foi enfraquecendo seu poder. Com isso, ela foi sendo submetida a pressões, principalmente do processo de secularização social próprio da modernização da região, mas também do avanço das igrejas protestantes, sobretudo as neopentecostais, e sua característica ética de valorização do trabalho, ou seja, de uma dimensão mundana.

Por consequência dessa influência, promoveu-se o surgimento de lideranças regionais e municipais, em um ambiente até então baseado no centralismo. $\mathrm{O}$ pentecostalismo traz novas possibilidades à relação entre religião e política nos países andinos, com vários membros ligados aos movimentos populistas atualmente exitosos

\footnotetext{
4 López (1998) faz referência à diferenciação conceitual que alguns pensadores, como Agamben e Mayorga, elaboram sobre populismo - que vê a categoria povo como uma entidade política integral, supostamente portadora da energia revolucionária da nação, algo próximo à população, o povo como um todo - e neopopulismo - que diria respeito ao povo visto como a parcela populacional excluída, o populacho, o povão. Laclau (2008) corresponde a esta definição ao falar em populus e plebs, mas torna mais complexa a análise ao dizer que a noção de povo do populismo (ou dos populismos, o "velho" e o "novo") se estabelece na relação em que a plebs se pretende populus, "es decir, una parcialidad que quiera funcionar como la totalidad de la comunidad” (LACLAU, 2008, p. 108).
} 
na região. Essa ligação faz com que a política andina incorpore uma dimensão prépolítica, emocional em lugar do racional. Já que os movimentos religiosos pentecostalistas introduzem nesse ambiente elementos místico-extáticos, não baseados na reflexão, mas na intuição, em sentimentos e em pré-juízos (VEGA-CENTENO, 1984).

Contudo, se com o passar do tempo o papel da Igreja Católica foi sendo relativizado, até um passado recente seu peso na elaboração da cultura política andina era expressivo. De acordo com López (1998), José Maria Velasco Ibarra, eleito presidente do Equador em 1934 (e depois em mais 4 oportunidades) não obteve o mesmo sucesso nas urnas em 1939, pelo fato de que deixou de contar com o apoio da Igreja Católica.

Conservador ad nativitem, filho predileto da Igreja até 1939, "Cavaleiro da Imaculada", e, naturalmente, homem casado pela Igreja com uma dama da sociedade de Quito, a hierarquia eclesiástica não perdoou a Velasco, e o censurou notoriamente, por haver começado a conviver publicamente com a argentina Corina Parral, na pacata sociedade de Quito dos anos trinta, o que foi considerado pela hierarquia como um rompimento com a "moral pública", cujo principal defensor era a Igreja Católica (LÓPEZ, 1998, p. 64, grifo do autor).

O autor reforça que a versão histórica tida por oficial remeteu a derrota de Velasco a uma alegada fraude eleitoral. Sem negar o peso desse fator, entretanto, López (1998) não deixa de atribuir à relação com a Igreja a causa magna do insucesso de Velasco Ibarra frente à população equatoriana em 1939, o que, sendo considerado em maior ou menor grau, reforça o quanto a religião participa do processo político, em especial na América Latina e na área andina, já naquele momento e ainda hoje.

\section{RELIGIÃO E CULTURA POLÍTICA NO BRASIL: DA LUTA CONTRA O REGIME MILITAR À ATUAÇÃO PARLAMENTAR NEOPENTECOSTAL}

Dentre os movimentos de base política nascidos dentro da Igreja Católica destaca-se a Teologia da Libertação. Muito presente no Brasil, ela tem uma forte ligação com elementos socialistas e com a religiosidade popular. Ao criticar a estrutura do poder econômico e da própria Igreja, promove a solidariedade aos necessitados e o questionamento do poder e sua dinâmica nos moldes trazidos pelos europeus e pelos ricos.

De fato, a Teologia da Libertação se insere em um contexto mais amplo em que importantes segmentos da Igreja Católica promoveram o desenvolvimento de grandes movimentos sociais e uma cultura política altamente engajada, com significativa ênfase 
na luta por direitos humanos, especialmente, contra os desmandos do regime militar brasileiro na segunda metade dos anos 1960. A repressão política tinha desestruturado quase totalmente a sociedade civil brasileira, cujas organizações só podiam atuar clandestinamente. "A única instituição que não tivera sua estrutura afetada fora a Igreja, que passou a ser a principal articuladora dos movimentos sociais" (VIOLA, 2007, p. 109).

Marques (2009, p. 196) sintetiza bem a importância da Igreja nesse momento e na história da política brasileira como um todo:

É importante destacar o papel da Igreja, tanto nos movimentos sociais - com a organização popular, baseada principalmente na 'Teologia da Libertação’ e na formação das Comunidades Eclesiais de Base (CEBs) - como nos movimentos de defesa dos direitos humanos - com a organização de centros de direitos humanos. Muitas organizações de direitos humanos no Brasil tiveram sua origem na Igreja.

Tendo um histórico de apoio aos governos e grupos políticos mais conservadores e muito embora de início tivesse apoiado o golpe de 1964, a Igreja dá uma guinada em sua orientação política no país, em meio ao regime militar e suas ações autoritárias inclusive contra seus membros.

Setores da Igreja haviam participado dos movimentos sociais que respaldaram o golpe militar de 1964, dando-lhe uma relativa base de apoio. Gradativamente, porém, em razão das denúncias de tortura e da perseguição de leigos católicos que participavam de diferentes movimentos sociais, bem como de religiosos e autoridades eclesiásticas, [...] houve uma mudança significativa nas relações entre o Estado autoritário e militarizado e a Igreja Católica. Mesmo antes de 1964, essas mudanças já se faziam presentes nas discussões travadas no interior dos setores ligados à Ação Social, notadamente no interior de movimentos como o de Educação de Base (MEB) com a Juventude Estudantil Católica (JEC), a Juventude Universitária Católica (JUC) e a Juventude Operária Católica (JOC) (VIOLA, 2007, p. 107).

Mesmo hoje a Igreja Católica mantém segmentos com forte atuação política, seja nas classes populares, através de ações como a Pastoral da Terra, que atua sobre a questão agrária, promovendo, por exemplo, a organização dos trabalhadores rurais e a fundação do MST; seja nos setores mais conservadores da sociedade brasileira, como a articulação da TFP e da Opus Dei.

De outra parte, assim como se processa na área andina, a última década tem visto um avanço considerável dos movimentos protestantes neopentecostais no cenário político brasileiro, trazendo novos elementos à cultura política do país e à relação entre religião e política. 
Nesse sentido, salta aos olhos a influência neopentecostal no jogo parlamentar, onde já se reconhece uma significativa influência da chamada bancada evangélica no Congresso Nacional.

Este grupo, que aglutina os deputados e senadores de orientação religiosa evangélica - protestante e, principalmente, pentecostal - tem grande força na defesa dos interesses a que se propõe proteger, dada a numerosa quantidade de parlamentares que a compõe, calculada pelo Departamento Intersindical de Assessoria Parlamentar (DIAP) em 66 legisladores federais para a legislatura 2011-2014. Isso permite à bancada evangélica barganhar com outros grupos congêneres, como a bancada ruralista, apoio em votações e demais procedimentos legislativos, em troca de sustentação recíproca.

Apesar de seu caráter suprapartidário, a bancada evangélica (ou Frente Parlamentar Evangélica, como começou a ser oficialmente chamada em 2003) é una nos interesses dos setores evangélicos que compõem a base eleitoral dos parlamentares. Conforme Santos e Caparelli (2004, p. 14),

[...] a atuação da chamada "bancada evangélica" no Congresso apenas observa unidade no que diz respeito às questões relativas aos princípios morais religiosos, como, por exemplo, nas circunstâncias de votação de projetos relativos à descriminalização do aborto ou à aprovação da parceria civil entre pessoas do mesmo sexo.

Porém, ainda que com menor coesão, outro ponto de convergência dos evangélicos no Congresso se dá nas comissões temáticas que discutem questões ligadas aos meios de comunicação, uma vez que de forma crescente as igrejas evangélicas brasileiras se utilizam dos espaços midiáticos, justificando seu interesse sobre o assunto das concessões de outorgas de radiodifusão no país (SANTOS; CAPARELLI, 2004), o que lhes permite praticar uma forma de proselitismo eletrônico muito bem sucedido.

Comprova também a relevância dos evangélicos na política brasileira a aliança feita nos pleitos à Presidência da República em 2002 e 2006, quando o presidenciável Luís Inácio Lula da Silva, eleito em ambas as oportunidades, trouxe para sua chapa o senador José Alencar, do então PL (Partido Liberal)5, considerado por alguns analistas como o partido dos evangélicos, por contar com grande número de deles entre seus filiados (LOBO, 2004; MARTINEZ, 2007).

\footnotetext{
5 Após fundir-se em 2006 com o PRONA (Partido de Reedificação da Ordem Nacional, de orientação ultraconservadora), o PL deu origem ao hoje PR (Partido da República). Assim, percebe-se que a antiga denominação ligada ao ideário do liberalismo não correspondia à sua verdadeira orientação política, embora desde o primeiro mandato de Lula, tenha feito parte da base parlamentar do Presidente, apoiando, portanto, o PT, partido posicionado na faixa esquerda do espectro político.
} 


\section{CONSIDERAÇÕES FINAIS}

Os escritos aqui apresentados remetem à consideração cada vez maior da religião como elemento altamente relevante na concepção de uma cultura política, não só na América Latina, mas de forma muito peculiar por aqui, seja para avalizar o populismo na área andina, seja para fomentar o protagonismo político no Brasil ditatorial e do presente, seja para fazer avançar os interesses das Igrejas neopentecostais no meio institucional do país.

Apesar do processo de racionalização secular da sociedade mundial, especialmente a civilização ocidental, a religião nunca deixou de ocupar um lugar de destaque na elaboração da visão de mundo das diferentes culturas. Mesmo onde a secularização foi mais profunda, a religião é altamente relevante na percepção que as pessoas criam sobre a realidade; realidade esta que elas mesmas constroem cotidianamente, retroalimentando essa importância.

A relação da dimensão religiosa com a política não é pouco significativa. Dessa forma, a religião serve não só à elaboração da compreensão de mundo das pessoas, como também à legitimação de determinados sistemas políticos, os quais, embora estruturados sobre bases racionais, fazem uso de elementos próprios do campo religioso para se sedimentar como proposta política, hegemônica ou contrahegemônica.

Se sobre o sistema político em si a influência da religião e da religiosidade conceito mais amplo, que envolve a dimensão não institucional - é evidente, quase incontestável, como negar, então, essa influência sobre a concepção da cultura política, que tanto reflete quanto compõe esse mesmo sistema político?

Se o dito mundo desenvolvido, que levou às últimas consequências o processo de modernização racional - com marcantes condicionamentos sobre a política -, tem ampliado o papel da religião na conformação de sua cultura política, cujo exemplo marcante foi a eleição de Bush "filho" em 2004, o que se dirá da América Latina, sobretudo sua porção hispânica (mas também no Brasil), que até bem pouco tempo tinha na Igreja Católica sua mais forte instituição social e que contemporaneamente tem visto o significativo crescimento dos movimentos neopentecostais?

Seja no norte do mundo, seja na América Latina, a cultura política, isto é, os valores, as atitudes e as opiniões dos atores políticos, tem cada vez mais se orientado por aspectos próprios da dimensão pré-política característica do universo religioso. 


\section{REFERÊNCIAS}

ALMOND, Gabriel. Uma teoria política comparada. Rio de Janeiro: Zahar, 1972. $206 \mathrm{p}$.

BAQUERO, Marcelo. A desconfiança como fator de instabilidade política na América Latina. In: BAQUERO, Marcelo; CASTRO, Henrique C. Oliveira de; GONZÁLEZ, Rodrigo S. A construção da democracia na América Latina: estabilidade democrática, processos eleitorais, cidadania e cultura política. Porto Alegre: UFRGS; Canoas: Centro Educacional La Salle, 1998. p. 13-29.

CASTRO, Henrique C. Oliveira de. Cultura política, democracia e hegemonia: uma tentativa da explicação do comportamento político não-democrático. In: BAQUERO, Marcelo; CASTRO, Henrique C. Oliveira de; GONZÁLEZ, Rodrigo S. (orgs.). A construção da democracia na América Latina: estabilidade democrática, processos eleitorais, cidadania e cultura política. Porto Alegre: UFRGS; Canoas: Centro Educacional La Salle, 1998. p. 30-49.

EVANGÉLICOS crescem no Congresso; PSC tem mais representantes. o6 out. 2010. Disponível em: <http://www.diap.org.br/index.php/eleicoes2010/bancadas-suprapartidarias/bancada-evangelica-cresce-no-congresso $>$. Acesso em 28 dez. 2010.

HABERMAS, Jürgen. Religião na esfera pública. Pressuposições cognitivas para o "uso público da razão" de cidadãos seculares e religiosos. In: HABERMAS, Jürgen. Entre naturalismo e religião: estudos filosóficos. Rio de Janeiro: Tempo Brasileiro, 2007. p. 129-167.

LACLAU, Ernesto. La razón populista. Buenos Aires: FCE, 2008.

LOBO, Chico. Talibanização da mídia evangélica no Brasil. 16 nov. 2004. Disponível em: <http://www.freelists.org/post/radiolivre/TALIBANIZAOEVANGLICA-NO-BRASIL>. Acesso em 28 dez. 2010.

LÓPEZ, Rafael Quintero. O debate atual sobre o populismo. In: BAQUERO, Marcelo; CASTRO, Henrique C. Oliveira de; GONZÁLEZ, Rodrigo S. (orgs.). A construção da democracia na América Latina: estabilidade democrática, processos eleitorais, cidadania e cultura política. Porto Alegre: UFRGS; Canoas: Centro Educacional La Salle, 1998. p. 30-49.

MANSILLA, Hugo C. F. Aspectos rescatables del mundo premoderno. Santa Cruz de la Sierra, Bolívia: El País, 2007. 182 p.

Elementos introductorios al concepto de cultura política con especial referencia al area andina. 2010. 16 p. Texto de referência produzido para a disciplina Seminário de Política, ministrada pelo autor no Programa de PósGraduação em Ciências Sociais da Universidade do Vale do Rio dos Sinos - UNISINOS, em 2010/2.

MARQUES, Gorete. Movimento dos direitos humanos em São Paulo: desafios e perspectivas. In: BITTAR, Eduardo C. B. (org.). Direitos humanos no século XXI: cenários de tensão. Rio de Janeiro: Forense universitária; São Paulo: ANDHEP; Brasília: SEDH, 2009. p. 194-200. 
MARTINEZ, João Flávio. A força do senhor. 28 set. 2007. Disponível em: $<$ http://www.cacp.org.br/midia/artigo.aspx?lng=PT-

BR\&article $=1129 \&$ menu $=16 \&$ submenu $=5>$. Acesso em 28 dez. 2010.

MORANDÉ, Pedro. Cultura y modernización en América Latina. Santiago, Chile: PUC, 1984

OAKESHOTT, Michael. La política de la fé y la política del escepticismo. México: FCE, 1998. 181 p.

ROKEACH, Milton. Crenças, atitudes e valores. Rio de Janeiro: Interciência, 1981. 178 p.

SANTOS, Suzy dos; CAPPARELLI, Sérgio. Crescei e multiplicai-vos: a explosão religiosa na televisão brasileira. Intexto, Porto Alegre, v. 2, n. 11, p. 1-24, jul./dez. 2004. Disponível em: <http://seer.ufrgs.br/intexto/article/view/4071/4446>. Acesso em 28 dez. 2010.

VEGA-CENTENO, Imelda. Los pobres, los jóvenes y la Iglesia. Lima: MIEC, 1984.

VÉLIZ, Claudio. La tradición centralista de América Latina. Barcelona, Espanha: Ariel, 1984. 343 p.

VIOLA, Solon E. A. Direitos Humanos e democracia no Brasil. São Leopoldo: Unisinos, 2007. 220 p. 